\title{
Communication
}

\section{Moving from Directives toward Audience Empowerment: A Typology of Recycling Communication Strategies of Local Governments}

\author{
Donghee Lee ${ }^{1,2, *}$ and Janice L. Krieger ${ }^{1,2,3,4}$ \\ 1 STEM Translational Communication Center, University of Florida, Gainesville, FL 32611, USA; \\ janicekrieger@ufl.edu \\ 2 Department of Advertising, College of Journalism and Communications, University of Florida, Gainesville, \\ FL 32611, USA \\ 3 Clinical and Translational Science Institute, University of Florida, Gainesville, FL 32610, USA \\ 4 Department of Health Outcomes \& Biomedical Informatics, University of Florida, Gainesville, FL 32610, USA \\ * Correspondence: dongheelee@ufl.edu
}

Received: 8 February 2020; Accepted: 30 March 2020; Published: 30 March 2020

\begin{abstract}
Recent changes in the global economy make it imperative for U.S. recycling programs to reduce contamination, however, little is known about how local municipalities are responding to this need. The implementation of the Chinese National Sword policy banned most U.S. imported solid waste in 2018, but there has been an increased focus on implementing recycling education campaigns. To date, there has been little empirical attention on how these campaigns are being developed and whether they are effective for increasing recycling and reducing contamination. The goal of the current study is to understand how recycling communication campaigns are being developed and implemented at the municipal level. To accomplish this, we conducted in depth-interviews with recycling coordinators, representing 30 counties within a large and diverse state to identifying the current message development and distribution strategies. Counties were selected to ensure the balanced representation of geographical (urban/rural) and recycling participation (low/middle/high). Findings illustrate six distinct types of recycling communication patterns employed in municipal solid waste county governments. We compare and contrast the benefits and challenges associated with communicating about recycling. The implications of these findings for developing a communication training to advance current campaign efforts in the local context are discussed.
\end{abstract}

Keywords: recycling contamination; recycling communication; science knowledge translation; information deficit; communication accommodation

\section{Introduction}

Clear and understandable local government communication is critical to improve municipal solid waste (MSW) recycling management; out of 262 million tons of MSW that are generated, only about 34.7 percent of materials were recovered from recycling or composting in the USA in 2015 [1]. Recent changes in the global economy have increased the need for effective recycling communication, to reduce contamination during the waste disposal process. For this research, recycling contamination refers to a sorting behavior that places materials into an incorrect recycling bin or disposes of inadequately cleaned materials and consequently damages other recycled goods. The implementation of the Chinese National Sword policy in 2018 has banned most of the foreign waste import, causing an international recycling crisis. The initiative has particularly affected the solid waste management and recycling industries in primary exporting nations such as America, costing hundreds of millions of solid waste trade values [2,3]. As a result, there has been an increased focus on 
the development and implementation of recycling education campaigns to reduce contamination while increasing recycling participation. Notable examples of these nationwide and statewide campaigns include "Let's Recycle right!" by Recycle Across America, "I want to be recycled" by Keep America Beautiful, and the Florida Department of Environmental Protection's "rethink, reset, recycle" movement. However, there has been little empirical attention to how these campaigns are being developed and implemented. Moreover, it is unknown whether they are effective for increasing recycling and reducing contamination.

Local municipal information can improve residential recycling participation by increasing issue relevance and ownership more than mass media campaigns [4]. Therefore, identifying and understanding how recycling information is currently communicated at the local level is critical to fostering correct individual MSW recycling behaviors. In Florida, there has been a statewide push for recycling education campaigns to meet the $75 \%$ statewide recycling goal. However, there is a visible geographical disparity in recycling rates, that range from $1 \%$ to $72 \%$ across counties [5]. Per the Florida Health Department guidelines [6], the majority of the low recycling counties are classified as rural, while most of the high recycling counties are classified as urban. The regional recycling discrepancy signals a need to investigate the current messages in local educational campaigns, to improve the recycling information translation process, to optimize residential recycling outcomes across all counties. The current study aims to understand how recycling communication campaigns are practiced at the municipal level.

In general, environmental problems are perceived as the byproduct of maladaptive human behaviors, that can be solved by altering the problem-inducing behaviors [7]. Understandably, recycling studies have primarily examined the influence of psychosocial factors associated with recycling behavior at the individual level, such as attitudes [8,9], social norms [10,11], and demographic factors, including age [12,13] and socioeconomic status [14]. However, knowledge has been widely considered as a key contributor and predictor of recycling [15-17]. Typically, the simple availability of instructions can improve overall community recycling participation [18]. Knowledge can also lead to a greater sense of competency and motivation to participate in specific waste disposal behaviors in individuals [4]. However, exclusive focus on increasing knowledge can create and reinforce the idea of information deficit, which claims that the mere existence of information can sufficiently encourage people to perform the desired behavior [19]. This perception views experts as a "repository of knowledge" and expects a successful, one-way transmission of information to the nonexpert audience [20].

However, the one-way information deficit approach fails to explain that individuals have their own biases, goals, and literacy levels, all of which mediate the information translational process [19]. Typically, experts believe that the major challenges of science communication involve lack of education and misinformation from media [21]. While access to accurate information is a piece of the process, it is also important to recognize that audience interpretations and opinions of a scientific issue vary, based on the current public discourse on the scientific findings [22] and the framing of evidence [20] or recommendations [23].

Despite the widespread use of mass media campaigns to shape audience attitudes and behavioral intentions surrounding the environmental issues, there is limited evidence that campaigns influence specific individual behaviors without immediate consequences, such as recycling [24]. Furthermore, interpersonal communication has been shown to be more effective than mass media in raising awareness of sustainability [25]. In the recycling context, inconclusive findings on the predictive role of knowledge on recycling behavior [10], highly subjective and inaccurate public recycling knowledge patterns $[10,26]$, and a wide value-action gap between the perceived importance and lack of actual participation in recycling [13,27-29] further challenge the idea of the one-way communication model as the "appropriate status quo." This suggests a need to implement a dialogic science communication approach [19]. 
Engaging both experts and nonexperts through dialogic communication facilitates a shared meaning-making process of scientific knowledge, that is not only mutually understandable and usable, but also reflective of the unique needs and diverse expertise of the audience [19,20]. Specifically, effective behavioral changes have ensued from culturally adapted educational interventions that are established on trust and relationship building with key community stakeholders [30,31]. Additional instances of informal public engagement with positive outcomes include science festivals [32] and university science lecture series [33], that facilitate interactions between experts and non-experts. A systematic evaluation of municipal recycling education campaigns using a communication science framework can facilitate the move towards dialogic communication practices. Therefore, the study identifies the current recycling education campaign message development and distribution practices, to illuminate opportunities to effectively translate recycling information and improve behavioral outcomes in the local context.

\section{Materials and Methods}

\subsection{Participants and Recruitment}

Recycling coordinators of each county oversee the solid waste and recycling management program, including related educational activities. Understanding perspectives of these public officials is critical, because they determine the development and delivery of key recycling information to community residents, to ensure appropriate disposal behaviors. To meet this need, the study purposively sampled 30 county recycling coordinators that were preselected based on the (1) geography (rural/urban), and (2) recycling rate (high/middle/low) in a southeastern state. Contact information for participants and the county recycling rate were retrieved from the official statewide government website. The document was reorganized into two separate parts: rural and urban counties, each of which was sorted by descending recycling rates to identify the target counties. The disproportionate rural recycling rates made it imperative to separately examine urban and rural counties separately, to equitably reflect the county recycling programs. The geographical classification of counties followed the rural county list provided by the official health department of the state [6]. Following Institutional Review Board (IRB) approval, a research assistant initially contacted participants through email and followed up with phone calls to schedule interviews. To facilitate the research process, an independent public relations consultant was contracted to assist with the participant accrual.

To provide a balanced representation of geography and recycling rate, 15 counties were recruited for each geographic designation, consisting of the highest, middle, and lowest recycling rates. The recycling rates reflect the percentage of each county's traditional recycling credit, as published by an official state report in which the research was conducted. The state environmental department defines the county traditional recycling credits as the amount of energy generated by the total collected solid waste after being processed in the recovery facility, except for renewable energy. The recycling rate (high/middle/low) in this study reflects the order by which each county was arranged, based on the number of its recycling credits as of 2017. For urban counties, high recycling rates ranged from $58 \%$ to $72 \%$; middle recycling rates ranged from $40 \%$ to $48 \%$; and low recycling rates ranged from $12 \%$ to $19 \%$. For rural counties, high recycling rates ranged from $1 \%$ to $7 \%$; middle recycling rates ranged from $11 \%$ to $18 \%$; and low recycling rates ranged from $29 \%$ to $56 \%$. Each recycling rate criterion consisted of five counties.

Each target participant was contacted, five times maximum, by phone and email. If the participants were nonresponsive, the researcher moved forward with the next county on the list in a hierarchal order. The recruitment script was revised from the generic focus (e.g., presenting the purpose of study and highlighting credentials of the primary investigators) to emphasizing the partnership with the statewide government and desirability and value of the selected county's participation. See Table 1 for interview participant characteristics. 
Table 1. Typology of Municipal Recycling Communication Strategies.

\begin{tabular}{|c|c|c|}
\hline \multirow{2}{*}{ Campaign Customization } & \multicolumn{2}{|c|}{ Communication Accommodation } \\
\hline & Deficit Reduction Approach & Translational Approach \\
\hline Audience-Centric & $\begin{array}{l}\text { Strengths: Education increases } \\
\text { accessibility and retention } \\
\text { of information. } \\
\text { Weaknesses: Knowledge is not a } \\
\text { strong predictor of } \\
\text { behavioral changes. }\end{array}$ & $\begin{array}{l}\text { Strengths: Empowers audience } \\
\text { through building ownership of } \\
\text { the issue. } \\
\text { Weaknesses: Inappropriate during } \\
\text { urgent public crisis requiring } \\
\text { compliance of the law. }\end{array}$ \\
\hline Multiple Channels & $\begin{array}{l}\text { Strengths: Facilitates timely and } \\
\text { extensive delivery and enforcement } \\
\text { of guidelines. } \\
\text { Weaknesses: Overexposure to } \\
\text { unclear guidelines can generate } \\
\text { malpractice from misunderstanding. }\end{array}$ & $\begin{array}{l}\text { Strengths: Allows simultaneous } \\
\text { interaction with the mass group } \\
\text { of audience. } \\
\text { Weaknesses: Insufficient for } \\
\text { long-lasting retention or practice of } \\
\text { the presented information. }\end{array}$ \\
\hline Single Channel & $\begin{array}{l}\text { Strengths: Expedites the } \\
\text { information dissemination process. } \\
\text { Weaknesses: Leads to apathy and } \\
\text { disinterest towards information. }\end{array}$ & $\begin{array}{l}\text { Strengths: interpersonal } \\
\text { communication helps reduction of } \\
\text { violating certain guidelines. } \\
\text { Weaknesses: Knowledge translation } \\
\text { is limited to specific contexts } \\
\text { and contents. }\end{array}$ \\
\hline
\end{tabular}

The research did not collect primary data pertaining to proprietary information involving the waste collection procedure, recovery, and resident payment model of each county. However, the research team retrieved information regarding population, recycling rates, total collected amount of municipal solid waste (MSW), and total number of units participating in curbside recycling, from an official state department database. See Table 2 for details.

Table 2. Demographics of interview participants.

\begin{tabular}{|c|c|c|c|c|c|c|}
\hline \multirow[b]{2}{*}{ ID $^{1}$} & \multicolumn{4}{|c|}{ Urban Counties } & \multirow[b]{2}{*}{$\begin{array}{c}\text { Total MSW } \\
\text { Collected } \\
\text { Tons }^{3}\end{array}$} & \multirow[b]{2}{*}{$\begin{array}{l}\text { Single Family } \\
\text { Curbside } \\
\text { Units }\end{array}$} \\
\hline & $\begin{array}{l}\text { Recycling } \\
\text { Rate }\end{array}$ & $\begin{array}{c}\text { Years of } \\
\text { Experience } \\
\text { with the County } \\
\text { Government }^{2}\end{array}$ & Population $^{3}$ & $\begin{array}{c}\text { Unadjusted } \\
\text { Recycling } \\
\text { Rate }^{3}\end{array}$ & & \\
\hline 1 & High & 18 years & 120,700 & $72 \%$ & 300,354 & 52,998 \\
\hline 2 & High & 4 years & 287,899 & $65 \%$ & 707,783 & 74,777 \\
\hline $3-1$ & High & $3 \frac{1}{2}$ years & 171,484 & $72 \%$ & 835,749 & 75,704 \\
\hline $3-2$ & High & 30 years & & & & \\
\hline $3-3$ & High & 18 years & & & & \\
\hline 4 & High & 9 years & 936,811 & $58 \%$ & $2,958,149$ & 294,927 \\
\hline 5 & High & $<1$ year & 148,962 & $64 \%$ & 514,319 & 53,080 \\
\hline 6 & Middle & 18 years & 521,745 & $40 \%$ & $1,115,115$ & 178,432 \\
\hline $7-1$ & Middle & 16 years & 407,260 & $41 \%$ & $1,243,176$ & 148,237 \\
\hline $7-2$ & Middle & $6 \frac{1}{2}$ years & & & & \\
\hline $8-1$ & Middle & 20 years & $1,411,246$ & $45 \%$ & $3,447,795$ & 420,946 \\
\hline $8-2$ & Middle & 15 years & & & & \\
\hline 9 & Middle & 14 years & 143,801 & $48 \%$ & 188,262 & 69,346 \\
\hline 10 & Middle & 22 years & 454,757 & $40 \%$ & 705,165 & 146,464 \\
\hline
\end{tabular}


Table 2. Cont.

\begin{tabular}{|c|c|c|c|c|c|c|}
\hline \multicolumn{7}{|c|}{ Urban Counties } \\
\hline ID $^{1}$ & $\begin{array}{c}\text { Recycling } \\
\text { Rate }\end{array}$ & $\begin{array}{c}\text { Years of } \\
\text { Experience } \\
\text { with the County } \\
\text { Government }^{2}\end{array}$ & Population ${ }^{3}$ & $\begin{array}{c}\text { Unadjusted } \\
\text { Recycling } \\
\text { Rate }^{3}\end{array}$ & $\begin{array}{c}\text { Total MSW } \\
\text { Collected } \\
\text { Tons }^{3}\end{array}$ & $\begin{array}{l}\text { Single Family } \\
\text { Curbside } \\
\text { Units }\end{array}$ \\
\hline 11 & Low & 27 years & 208,549 & $18 \%$ & 271,651 & 70,396 \\
\hline $12-1$ & Low & 12 years & 143,801 & $48 \%$ & 188,262 & 69,346 \\
\hline $12-2$ & Low & 3 years & & & & \\
\hline 13 & Low & 11 years & $2,733,125$ & $18 \%$ & $5,062,400$ & 512,920 \\
\hline 14 & Low & 28 years & 50,418 & $13 \%$ & 49,675 & 17,994 \\
\hline 15 & Low & 21 years & 229,715 & $19 \%$ & 435,273 & 81,493 \\
\hline 16 & High & 30 years & 11,562 & $46 \%$ & 17,769 & 5917 \\
\hline 17 & High & $4 \frac{1}{2}$ years & 17,224 & $31 \%$ & 5989 & 6607 \\
\hline 18 & High & 25 years & 102,047 & $56 \%$ & 122,095 & 48,777 \\
\hline 19 & High & $2 \frac{1}{2}$ years & 76,889 & $54 \%$ & 656,783 & 32,629 \\
\hline 20 & High & 33 years & 48,263 & $29 \%$ & 36,731 & 18,010 \\
\hline $21-1$ & Middle & 13 years & 39,057 & $17 \%$ & 56,522 & 8862 \\
\hline $21-2$ & Middle & 5 years & & & & \\
\hline $21-3$ & Middle & $<1$ year & & & & \\
\hline 22 & Middle & 20 years & 41,015 & $12 \%$ & 33,345 & 19,035 \\
\hline 23 & Middle & 8 years & 8479 & $12 \%$ & 3826 & 3258 \\
\hline 24 & Middle & N/A & 337,287 & $14 \%$ & 418,869 & 110,200 \\
\hline 25 & Middle & 16 years & 41,551 & $18 \%$ & 173,504 & 14,205 \\
\hline 26 & Low & 5 years & 25,887 & $3 \%$ & 19,980 & 7903 \\
\hline 27 & Low & 15 years & 65,301 & $7 \%$ & 178,978 & 25,320 \\
\hline 28 & Low & $20 \frac{1}{2}$ years & 16,726 & $2 \%$ & 11,078 & 6600 \\
\hline 29 & Low & 2 years & 35,621 & $11 \%$ & 46,518 & 11,876 \\
\hline 30 & Low & 22 years & 14,611 & $5 \%$ & 12,670 & 5713 \\
\hline
\end{tabular}

1. The order of participant ID does not reflect the hierarchy of recycling rates, as represented from the official state report. ${ }^{2}$ Inconsistent metrics for reporting the years of experience, as some participants reported a calendar year (e.g., since 2008), while others reported the length of time (e.g., four and half years). If a participant had served the county prior to assuming the current position, the total length of time served in the county was reported. To maintain consistency of data, researchers determined the data collection time period (2019) as the starting point to calculate the total years of experience. In addition, not all counties had a recycling program. In such instances, the years affiliated with the county government were reported and documented, instead of the recycling department. 3. Data were retrieved from the 2017 Final Disposition of Municipal Solid Waste Report from the official state government website. Traditional recycling credits exclude data for renewable energy and landfill-based energy.

\subsection{Interview Protocol and Analysis}

The semi-structured interview was guided by an IRB approved script, to ensure coverage of the core questions surrounding recycling communication practices. Before beginning the interview, participants were assured that the goal of the study was to learn about their thoughts, and that there were no right or wrong answers. The interview guide and recruitment message were developed initially by one member of the research team, which was reviewed and edited based on the feedback of other investigators. A total of five graduate and undergraduate research assistants from the investigative team conducted interviews from October 2018 to April 2019 using the same script, although the leading 
interviewer completed $70 \%$ of the interviews. The interviews were audio-recorded and transcribed for analysis. See Supplementary Materials for the interview script.

The interview data were thematically analyzed using the constant comparative method [34]. The researchers open-coded 30 transcripts to identify patterns of ideas and emerging themes within the data. The initial codebook was iteratively developed, to ensure that the codes, properties, and data excerpts in the codebook were pertinent and representative of the key themes. Finally, axial coding was performed to assign the data to the appropriate codes.

\section{Results}

The findings established two dimensions of the recycling message designing and distribution strategies: communication accommodation and campaign customization. The interaction of these two dimensions produced six qualitatively distinct communication types. The types include single-channel deficit-reduction, multi-channel deficit-reduction, audience-centric deficit-reduction, single-channel translation, multi-channel translation, and audience-centric translation.

First, communication accommodation describes the degree to which recycling communication is adjusted based on audience characteristics [35]. Two types of accommodation types emerged: deficit reduction and translation. The deficit reduction approach provides educational efforts to increase awareness and knowledge about recycling and contamination. The translational approach reflects an interactive approach, characterized by the interpretation of recycling information using languages and expressions that are understandable to the intended audience. Second, campaign customization refers to the extent to which messages use elements that are relevant and relatable to the intended audience groups [36]. Three types of customization emerged: single channel, multi-channel, and audience-centered approach. Single channel reflects simply providing access to recycling information; multichannel depicts using several channels or strategies to increase the message exposure, regardless of audience wants and needs; audience-centered describes perspective-taking in message planning, development, and implementation. See Table 1 for a visual representation of the typology.

\subsection{Single Channel Deficit Reduction Approach}

The single channel deficit reduction approach refers to using one channel or outlet to display the county recycling information. Examples include exhibiting instructions at drop-off facilities or on county websites, and a biannual publication of the local newspaper advertisements, to promote a free-waste disposal event for community clean-up. The primary message communicated in this approach involved specific county waste disposal guidelines. These messages were limited to information about the county recycling policies, waste management schedules, and instructions on acceptable recyclable materials. Due to the goal of these messages being to promote an awareness of and an adherence to county policies and rules related to recycling, the status of county guidelines and recycling program determined the content and update frequency of the messages. If the rules remained unchanged, so did the recycling messages. One participant noted, "It's always the same. What can we recycle, what do we put in our carts. For us, our message hasn't changed in years... So as far as what we recycle, what we take, and any of that stuff that hasn't changed, so that's a continuous message that we have out there via the website and everything." (Participant 22)

This approach was prevalent in counties with structural restrictions, including the budget for the educational campaign or the county recycling program. A shortage of human and financial resources was a major hindrance to the ability of counties to develop and implement creative campaign strategies. Despite the availability of county websites, lack of funding often deterred digital visibility of the county recycling program. One participant said, "Okay. 'cause really, truthfully, the only way that we've ever communicated is through the newspaper. The county has a small website, but it's very underfunded and outdated. So, let's put it that way." (Participant 23) 


\subsection{Multichannel Deficit Reduction Approach}

The multichannel deficit reduction approach refers to using various marketing strategies, media channels, and persuasive message design techniques to maximize information exposure. Examples include the simultaneous and timely distribution of messages via broadcast, print, digital, and social media, incorporation of visual elements, and implementation of seasonal campaigns to capture audience attention. Counties using this approach believed that the repetition and mass dissemination of instructions was the most important and effective solution to promote overall recycling participation and correct disposal behavior. This approach was more salient in counties with higher population density and more financial and human resources to support communication activities. Urban and higher resource counties explicitly acknowledged a significant amount of budget allocated towards recycling education programs to execute a sophisticated and exhaustive recycling campaign. Messages were distributed using multiple channels and platforms for both paid and unpaid campaigns. A participant said,

“... I manage a budget of about 430,000 dollars that we use to purchase media, and that's television, radio, billboard, bus side, bus shelters ... I know there's more in there. Print, newspaper, magazines, weekly's ... We work with many different partners to try to get that message out. And that's the paid media." (Participant 8)

\subsection{Audience-Centric Deficit Reduction Approach}

The audience-centric deficit reduction approach was defined as segmenting the audience based on their preference and characteristics, to develop and distribute messages that are comprehensible, memorable, and actionable. Examples include simplifying messages, using wide-reaching channels and bilingual advertising (e.g., English and Spanish) to meet various wants and needs of the intended audience. A salient example includes a participant who cautioned against information overload and inconsistent messaging to prevent confusion and resistance towards the campaign message. The participant said, "We have a habit of putting too much information... We tend to over-educate and we shouldn't. Because, after a while, people say, 'I don't want to read that. Just gonna throw it in there, 'cause I'm not gonna read it.'" (Participant 5)

However, a dialectic tension appeared within the same participant's dialogue. Despite emphasizing the importance of catering to the audience needs in developing and distributing information, such understanding about the audience was based on untested optimistic assumptions about recycling intention. Instead of evaluating the accuracy of the assumptions about the preferred channels and messages, the participant focused on simplifying and repeating instructions to reduce information deficit. She said, "I think, for sure, people want to recycle, they want to do the right thing, and they're open to learn about it. It's just the education. It's key ... It's not if you're recycling. It's if you're recycling right, and that is just education, education, education." (Participant 5)

\subsection{Single Channel Translational Approach}

The single channel translational approach involves explaining recycling information to residents using interpersonal communication. Primary examples include face-to-face interactions between the county government and residents at the recycling collection site or phone inquiries. The goal of these interactions was to ensure correct disposal behaviors. The primary face-to-face interaction between collection site attendants and residents included monitoring and regulating the disposable trash at the recycling facilities. Examples included residents asking questions or recycling coordinators approaching site visitors. One participant said, "... I go to these sites. Even though we have somebody there, I may spend three or four hours there, and it just is generated by word of mouth because it a small county ... I know most everybody that's coming in there ... I'll walk up to them [and ask] ‘How are you doing?'” (Participant 28) 
One of the most widely utilized communication methods included phone calls, in which residents called the county government to clarify instructions related to waste disposal and management services. Most virtual interactions included passive answering to questions, yet active and conscious efforts to accommodate the audience needs and preference also existed. These counties demonstrated active efforts to prioritize the audience in ways that resembled a customer-service oriented approach. One participant said, "Our department ... actually answers the phone with a live human being. We do not change that. You do not get a message when you call here." (Participant 15)

\subsection{Multichannel Translational Approach}

The multichannel translational approach involves explaining recycling information to residents through individual interactions, using messages that are adapted to the specific audience characteristics and preferences. Examples include hosting community outreach events, recycling tours, presenting at local schools, and attending community organization meetings to increase program visibility, or to educate residents about sustainability and the waste management process. These interpersonal communication approaches provided an opportunity to simultaneously interact with the mass audience.

The use of mass, digital, and mobile media, including websites, social media, and mobile apps, facilitated reciprocal and timely communication with residents. A notable example includes incorporating interactive features in the county website (e.g., interactive question and answer (Q\&A) chat box allowing residents to submit questions and receive answers related to recycling), to enhance the effectiveness of the communication process. The participant noted the increased efficiency of using digital communication over the use of conventional phone calls. He said,

"It's called, Gov. Q\&A, where a resident can get on and pick the department they want to talk to, and they can actually ask a question, and it's directed to the appropriate personnel. And it's actually got a timeline on when it's supposed to be answered so that it doesn't fall through the cracks." (Participant 11)

Additional strategies included making appearances on live local radio shows. The types of live shows ranged from simple open question sessions to hosting game shows, to increase contamination knowledge through engagement. This strategy not only allowed direct communication between the government and residents, but also increased empathy and relatability towards the municipal solid waste department, to increase issue relevance towards recycling. One participant said, "One of the radio stations actually does a live broadcast as you're talking, so we get to be a little more personal about [recycling education]. We get there look like normal human beings, instead of multi-headed recycling coordinators." (Participant 15)

\subsection{Audience-Centric Translational Approach}

The audience-centric translation types refer to audience empowerment through active involvement of the audience in the recycling program. Examples include acknowledging their role in the recycling process, and a shared decision-making of the local waste management system. One county noted publishing an explicit statement, thanking the residents for recycling participation in the local newspaper advertisement. He said, "We thank the community for their efforts, and because of their efforts we were able to achieve XYZ percentage... So, we try to be inclusive of that when we do advertising." (Participant 3)

Additional examples include involving residents in the policy decision making process to customize the waste disposal system, to optimize the recycling outcomes. This approach occurred when the county waste management employees participated in community meetings, to directly interact with individual residents and key members of community organizations. Throughout the interactive process, residents were considered as stakeholders and equal partners rather than passive message receivers. This approach facilitated a collaborative learning and communicative experience. The county engaged the community residents in open and transparent conversations, to collaboratively 
identify, understand, and solve a problem. The same participant who thanked the residents also provided exemplar practice, such as transferring ownership and decision-making power for recycling to the community residents.

“... We visited all the homeowners' associations... And we empowered them, to a degree, by showing them the carts that we had and what our program was gonna be, and had them actually choose what size cart fit their community best ... By inviting them in and having a voice made them feel like they were making the decision, rather than us coming as government and saying 'Here's your 64 gallon cart, have a nice day." (Participant 3)

\subsection{Opportunities in Deficit Reduction and Translational Approach}

The principal viewpoint guiding the deficit reduction approach was one-way information transmission. In this approach, the audience was considered as a passive receiver, instead of a collaborator of knowledge. Major challenges associated with the deficit reduction approach include general apathy, disinterest towards recycling, and lack of behavioral shift in the audience. These challenges emerged across all campaign customization dimensions. A similar challenge was noted in the single and multichannel translational approach. Due to the fact that the common goal across the translation dimensions was to explain recycling information, the effectiveness of education in the single and multichannel campaign customization dimensions was limited to those already invested in the recycling issue. This contributed to a widening of the gap between high and low recyclers, who remained uninformed and disengaged. He said, "Obviously, I'm not catching the illegal dumpers, so I'm always talking to the good ones, the ones that are disheartened as well as I am about the illegal dumping. And then when I ... go out to the meetings there, you're preaching to the choir." (Participant 9)

The issue was addressed in the audience-centric translational approach, in which the audience demonstrated motivation to learn and change their behavior. The goal of recycling education in this approach was to increase understanding about the broader recycling systems, the role and impact of individual actions. Therefore, recycling information was conveyed and reshaped through open dialogues, by listening, observing, and encouraging questions to improve the recycling systems and the campaign messages. The active collaboration process empowered the audience to make and negotiate meanings associated with recycling, which led to high recycling participation and satisfactory communication outcomes.

"I think people are sometimes afraid to ask, because they don't want to be told they're doing something wrong. I think when you engage them, and open the dialogue, I think it is a lot more fruitful... They'll say, 'Now that you mentioned it, I had another question ... ' So, it goes from a confrontational, 'You're not recycling right,' to 'I want to learn how to do it right, and I want to know if I'm doing it right or not.' And that shift really is, to me, I think people learn better from that than just some pamphlet or flyer." (Participant 7)

\section{Discussion}

Each communication type reflects different goals, channels, messages, and strategies for municipal recycling communication. A notable distinction in the two communication accommodation dimensions is the level of audience engagement in the message development and distribution strategies. While the deficit reduction approach emphasized message exposure, the translational approach focused on the collaborative recycling meaning-making process with residents. Therefore, the effect of recycling campaigns in each dimension varied.

Notably, coordinators who prioritized information dissemination employed a deficit approach. Coordinators using a single channel deficit approach found a single channel deficit approach to expedite their information dissemination efforts, especially when they lacked appropriate communication modalities. While the simple availability of information was necessary to guide residents' disposal 
behaviors, the presence of information ensured neither attention nor engagement with the information. Apathy and disinterest in recycling was prevalent among community residents in counties employing this approach. Integrating one-on-one conversations on site or virtually engaging community members in dialogues can enable counties in this approach move towards a single translational approach.

Coordinators employed a multi-channel deficit approach when their goal was to maximize exposure and level of attention to the information. This approach can benefit the management of the public health crisis, by facilitating timely delivery and enforcement of guidelines. Additionally, such times involve heightened audience attention and greater willingness to comply to the issue. However, awareness does not ensure adequate understanding nor behavior to effective address the issue. For example, overexposure to unclear guidelines during an epidemic can generate misinformed malpractice of safety measures of the public. Practically, coordinators using this approach can move towards an audience-centric deficit approach, by tailoring their communication strategies to increase the comprehension and utility of information.

Coordinators employed an audience-centric approach to increase accessibility and retention of information to the intended audience group. However, behavioral willingness as a result of successful education does not always translate into behavioral changes. In addition, educational efforts in this approach involved personal assumptions of audience wants, instead of evidence. To optimize this strategy, coordinators can move towards an audience-centric translational approach and adapt their communication based on the responses of community members.

Translational approach emerged when coordinators prioritized interaction and reflection of the voices of the community. Coordinators using a single channel translational approach found that using interpersonal communication allowed them to accommodate the community needs to guide them to correct disposal behaviors. However, these interactions were limited to answering specific questions, instead of discussing the overall recycling guidelines. Therefore, knowledge translation was limited to specific contexts and contents. Practically, coordinators can move towards the multichannel translational approach by integrating information dissemination and community engagement, in addition to incorporating industry stakeholders to expand their communication platforms and delivery of message.

Coordinators adopted a multi-channel translational approach to engage in a simultaneous interaction with the mass group of audience using a relevant and relatable message. These coordinators understood the value of interactive communication. However, adapting messages to explain information may be insufficient for the long-lasting retention or practice of the information. For optimal recycling outcomes, coordinators in this approach can incorporate an audience-centric translational approach, to position their audience at the center of the communication decision making process.

Finally, coordinators employed an audience-centric translational approach to develop and implement a recycling program that reflected the core community values. This approach encouraged active contribution and involvement of the community, through instilling the ownership and identity associated with sustainability. Therefore, this approach is appropriate for creating a shared meaning and greater willingness and participation of sustainability. Coordinators should proactively maintain this approach through fostering relationships with community.

The deficit reduction and translational approach serve different purposes. First, information diffusion is a preceding step for audience empowerment, to collaboratively make a broader sociopolitical and economic impact. Without awareness of the new policies and the associated messages, the audience will lack the ability to create and negotiate meanings related to recycling.

Second, a clear and simple one-way message is necessary in times of emergency. A message that facilitates meaningful discussion about an issue may be inappropriate and dangerous. However, the recent shift in international recycling policies makes it imperative for local counties to engage their residents in open dialogues, to promote understanding about the political and economic implications to overcome the global recycling crisis. A highly customized translation message, that encourages questions and shared policy decision-making, is particularly valuable to promote recycling without 
jeopardizing residents' moral beliefs associated with conservation, while meeting varying rules and levels of resources in each county. An appropriate combination of the deficit reduction and translational approach can benefit the efforts towards recycling contamination reduction.

The varying degrees of communication approaches can differently shape individuals' motivations to recycle. For instance, community members in a single deficit approach might practice recycling to avoid penalties, while members in an audience-centric translational approach might recycle to perform civic duties and protect the community that they represent. Past research has noted the effect of intrinsic motivation on recycling $[8-11,13,16]$. One direction for future research would be to incorporate the communication approach identified from this study, to examine the role of individuals' environmental concerns [16], perceived inconvenience [13], attitudes towards recycling [8,9], and peer pressure $[10,11]$ on their willingness to reduce recycling contamination. Our findings indicate that integrating audience-centric translational approaches to tailor messages to individuals' intrinsic motivations can optimize message and recycling outcomes. Future studies could empirically examine the interplay of each of the six communication approaches with perceived social or social benefits of recycling to extend the current research.

\section{Conclusions}

The six communication types reflect the extent to which recycling information is customized and attuned to audience characteristics. Each type makes up a continuum of the channels and strategies that municipal governments utilize to exchange recycling information.

One end of the horizontal spectrum focuses on one-way education and reinforcement of the recycling instructions, while the other end of the spectrum promotes audience engagement and collaboration. While one approach is not necessarily better than the other, it is important to acknowledge the role and impact of communication on recycling campaigns and overall recycling outcomes. Our typology illustrates a map that counties can use as a guide to identify their current communication practices and move towards a direction that suits their unique goals and needs.

Therefore, it is important to recognize the strengths and weaknesses of each dimension when employing this model in practice. For single-channel campaigns, a deficit approach can expedite distribution of information, yet can result in apathy and disinterest among the audience. Interpersonal communication employed in the translational approach can help reduce violation of certain regulations, yet such an outcome is limited to specific contexts. For multi-channel campaigns, a deficit approach can facilitate the timely and wide-reaching dissemination of information, yet it can generate contamination from misunderstanding. A translational approach can allow simultaneous interaction with multiple community members, yet retention of information is unlikely. For audience-centric campaigns, deficit approach can enhance understanding and memorability of information, yet it may not translate into behavior. Conversely, a translational approach can empower the audience and create ownership of the issue, yet it may be inappropriate during urgent public crises.

As with all research, this study has limitations. First, the study sample is limited to one state that uniquely attracts a high tourist and retiree population. These transient residents may care less about recycling or are less likely to invest their time to learn about the issue. Conversely, retiree populations who moved from states with more stringent recycling rules may insist on maintaining their practice, without understanding the economic implications associated with recycling. Prevalence of the two groups with conflicting interests suggests that coordinators from this state must work collaboratively with their stakeholders and residents to develop messages that can be tailored to the target groups. Given the unique circumstances involving resident characteristics, challenges and examples found in the study might not apply to other states. In addition, not all participants within the original recruitment group were available for interview. While additional participants were recruited to meet the target sample size, unique insights and challenges associated with specific geographical and recycling programs from the original sample could have been omitted in the revised recruitment method. Regardless, the current study serves as a best-communication-practices guide for practitioners 
to adapt and implement in their campaigns. Specifically, examples of current practices provided in our typology demonstrate specific ways in which counties can use and modify to leverage their current campaign effort. Findings from this research provide a groundwork to develop a communication training intervention to optimize the recycling campaign outcomes.

\section{Supplementary Materials:}

Interview Script

Recycling Coordinator Tasks/Responsibilities

1. What is your background? (Education and work experience)

2. How long have you worked as a recycling coordinator for your county?

3. What are your day to day responsibilities as a recycling coordinator?

4. What percentage of time do you spend on recycling coordination? What are your other responsibilities?

\section{a. What about your staff? What do they do?}

Current knowledge of recycling problems

1. Tell me about a success story-what are you doing well?

2. What does your county want to improve?

3. Can you describe your county residents? (For interviewers: try to get the coordinators' awareness on their residents. Are they focusing on or missing certain demographic groups?)

a. [Consider language, income range, ethnic groups of residents]

4. What factors motivate your community to recycle?

5. What factors discourage your community from recycling?

Communication Channels and Messages

1. How do you currently distribute recycling information to your community?

[Consider channels and outlets for information exchange]

Probe: What other ways do you use?

Probe: Do you use social media?

2. What have you tried that worked well in your county?

3. What have you tried that worked poorly in your county?

4. How do you know what questions that your community members might have about recycling? Who and how do they contact?

5. What are the biggest challenges of communicating with your community members?

6. What kind of approach would work best for your community? What do you think your community would want?

7. What recycling message contents do you think your community members would like to see? What messages do you think they can relate to?

County website

1. What do you think about your county website?

2. Who updates your website? And how often is it updated?

3. Who updates your social media? And how often is it updated?

4. Have you received feedback about your website? If so, what was the feedback? 
Other media

1. Do you use any print media? Please explain.

2. Do you use any broadcast media (TV/radio)? Please explain.

3. Do you use billboards? Please explain.

Author Contributions: Conceptualization, D.L. and J.L.K.; methodology, D.L. and J.L.K.; formal analysis, D.L.; writing — original draft preparation, D.L.; writing—review and editing, J.L.K.; funding acquisition, J.L.K. All authors have read and agreed to the published version of the manuscript.

Funding: This research was funded by HINKLEY CENTER FOR SOLID AND HAZARDOUS WASTE MANAGEMENT, grant number PRO00017910. Publication of this article was funded in part by the University of Florida Open Access Publishing Fund.

Conflicts of Interest: The authors declare no conflict of interest. The funders had no role in the design of the study; in the collection, analyses, or interpretation of data; in the writing of the manuscript, or in the decision to publish the results.

\section{References}

1. Advancing Sustainable Materials Management: 2015 Fact Sheet. Available online: https://www.epa.gov/ sites/production/files/2018-07/documents/2015_smm_msw_factsheet_07242018_fnl_508_002.pdf (accessed on 1 August 2019).

2. Brooks, A.L.; Wang, S.; Jambeck, J.R. The Chinese import ban and its impact on global plastic waste trade. Sci. Adv. 2018, 4, eaat0131. [CrossRef] [PubMed]

3. Center for Ecotechnology. Available online: https://www.cetonline.org/what-is-the-national-sword (accessed on 5 June 2019).

4. Vicente, P.; Reis, E. Factors influencing households' participation in recycling. Waste Manag. Res. 2008, 26, 140-146. [CrossRef] [PubMed]

5. 2017 Traditional Recycling Credits by County. Available online: https://floridadep.gov/waste/wastereduction/documents/2017-traditional-recycling-credits-county (accessed on 1 April 2019).

6. Rural County List. Available online: http://www.floridahealth.gov/programs-and-services/communityhealth/rural-health/_documents/rual-counties-2000-2010.pdf (accessed on 1 April 2019).

7. Maloney, M.P.; Ward, M.P. Ecology: Let's hear from the people. Am. Psychol. 1973, 28, 583-586. [CrossRef]

8. DeYoung, R.D. Exploring the difference between recyclers and non-recyclers: The role of information. J. Environ. Syst. 1989, 18, 341-351. [CrossRef]

9. Prestin, A.; Pearce, K.E. We care a lot: Formative research for a social marketing campaign to promote school-based recycling. Resour. Conserv. Recycl. 2010, 54, 1017-1026. [CrossRef]

10. Oskamp, S.; Harrington, M.J.; Edwards, T.C.; Sherwood, D.L.; Okuda, S.M.; Swanson, D.C. Factors influencing household recycling behavior. Environ. Behav. 1991, 2, 494-519. [CrossRef]

11. Vermeir, I. Strong attitudes versus strong situations: Social pressure on recycling. In NA-Advances in Consumer Research; Ann, L., McGill, A.L., Shavitt, S., Eds.; Association for Consumer Research: San Francisco, CA, USA, 2009; Volume 36, pp. 601-603.

12. Biswas, A.; Licata, J.W.; McKee, D.; Pullig, C.; Daughtride, C. The recycling cycle: An empirical examination of consumer waste recycling and recycling shopping behaviors. J. Public Policy Mark. 2000, 19, 93-105. [CrossRef]

13. Kelly, T.C.; Mason, I.G.; Leiss, M.W.; Ganesh, S. University community responses to on-campus resource recycling. Resour. Conserv. Recycl. 2006, 47, 42-55. [CrossRef]

14. Howenstine, E. Market segmentation for recycling. Environ. Behav. 1993, 25, 86-102. [CrossRef]

15. Hornik, J.; Cherian, J.; Madansky, M.; Narayana, C. Determinants of recycling behavior: A synthesis of research results. J. Socio-Econ. 1995, 24, 105-127. [CrossRef]

16. Scott, D. Equal opportunity, unequal results: Determinants of household recycling intensity. Environ. Behav. 1999, 31, 267-290. [CrossRef]

17. Simmons, D.; Widmar, R. Motivations and barriers to recycling: Toward a strategy for public education. J. Environ. Educ. 1990, 22, 13-18. [CrossRef] 
18. Rhodes, R.E.; Beauchamp, M.R.; Conner, M.; de Bruijn, G.J.; Latimer-Cheung, A.; Kaushala, N. Are mere instructions enough? Evaluation of four types of messaging on community depot recycling. Resour. Conserv. Recycl. 2014, 90,1-8. [CrossRef]

19. Krieger, J.L.; Gallois, C. Translating science: Using the science of language to explicate the language of science. J. Lang. Soc. Psychol. 2017, 36, 3-13. [CrossRef]

20. Howes, L.M.; Kemp, N. Discord in the communication of forensic science: Can the science of language help foster shared understanding? J. Lang. Soc. Psychol. 2017, 36, 96-111. [CrossRef]

21. Beasley, J.C.; Nisbet, M. How scientists view the public, the media and the political process. Public Underst. Sci. 2011, 22, 644-659. [CrossRef]

22. Lewandowsky, S.; Gignac, G.; Vaughan, S. The pivotal role of perceived scientific consensus in acceptance of science. Nat. Clim. Chang. 2013, 3, 399-404. [CrossRef]

23. Neil, J.M.; Krieger, J.L.; Kalyanaraman, S.; George, T.J. Innovation or inconsistency? Framing colorectal cancer guidelines to improve public perceptions of updated screening recommendations. J. Lang. Soc. Psychol. 2017, 36, 14-27. [CrossRef]

24. Chan, K. Mass communication and pro-environmental behaviour: Waste recycling in Hong Kong. J. Environ. Manag. 1998, 52, 317-325. [CrossRef]

25. Stamm, K.R.; Clark, F.; Eblacas, P.R. Mass communication and public understanding of environmental problems: The case of global warming. Public Underst. Sci. 2000, 9, 219-237. [CrossRef]

26. Izagirre-Olaizola, J.; Fernández-Sainz, A.; Vicente-Molina, M.A. Internal determinants of recycling behaviour. Int. J. Consum. Stud. 2015, 39, 25-34. [CrossRef]

27. Ojala, M. Recycling and ambivalence: Quantitative and qualitative analyses of household recycling among young adults. Environ. Behav. 2008, 40, 777-797. [CrossRef]

28. Schultz, P.W.; Oskamp, S.; Mainieri, T. Who recycles and when? A review of personal and situational factors. J. Environ. Psychol. 1995, 15, 105-121. [CrossRef]

29. Stanes, E.; Klocker, N.; Gibson, C. Young adult households and domestic sustainabilities. Geoforum 2015, 65, 46-58. [CrossRef]

30. Baydala, L.; Fletcher, F.; Worrell, S.; Kajner, T.; Letendre, S.; Letendre, L.; Rasmussen, C. Partnership, knowledge translation, and substance abuse prevention with a first nations community. Prog. Community Health Partnersh. Res. Educ. Action 2013, 8, 145-155. [CrossRef]

31. Hahn, D.L.; Hoffmann, A.E.; Felzien, M.; LeMaster, J.W.; Xu, J.; Fagnan, L.J. Tokenism in patient engagement. Fam. Pract. 2017, 34, 290-295. [CrossRef]

32. Jensen, E.; Buckley, N. Why people attend science festivals: Interests, motivations and self-reported benefits of public engagement with research. Public Underst. Sci. 2014, 23, 557-573. [CrossRef]

33. AbiGhannam, N.; Kahlor, L.; Dudo, A.; Liang, M.; Rosenthal, S.; Banner, J.L. Expectancies and motivations to attend an informal science lecture series. Int. J. Sci. Educ. 2016, 6, 215-238. [CrossRef]

34. Glaser, B.; Strauss, A. The Discovery of Grounded Theory; Aldine Publishing Company: Hawthorne, NY, USA, 1967.

35. Giles, H. Communication accommodation theory. In Engaging Theories in Interpersonal Communication: Multiple Perspectives; Baxter, L.A., Braithewaite, D.O., Eds.; Sage Publications: Thousand Oaks, CA, USA, 2008; pp. 161-173.

36. Krieger, J.L.; Neil, J.M. Communication and recruitment to clinical research studies. In Oxford Research Encyclopedia of Communication; Oxford University Press: Oxford, UK, 2016.

(C) 2020 by the authors. Licensee MDPI, Basel, Switzerland. This article is an open access article distributed under the terms and conditions of the Creative Commons Attribution (CC BY) license (http://creativecommons.org/licenses/by/4.0/). 